\title{
Tariff Regulation on the base of Weather and Seasonal Changes in Transportation Environment
}

\author{
Arkadii Anatol'evich Simdiankin 1*, Pavel Sergeevich Probin ${ }^{1}$, Lyudmila Petrovna Belyu ${ }^{1}$, \\ Natalia Alekseevna Prodanova ${ }^{2}$, Tatiana Leonidovna Melekhina ${ }^{3}$, Savda Yaragievna \\ Yusupova ${ }^{4}$
}

${ }^{1}$ Russian state university of physical education, sport, youth and tourism (SCOLIPE), Sireneviy boulevard, 4, Moscow, 105122, Russian Federation ${ }^{2}$ Plekhanov Russian University of Economics, Stremyanny lane, 36, Moscow, 117997, Russian Federation ${ }^{3}$ Financial University under the Government of the Russian Federation, Shcherbakovskaya Str, 38, Moscow, 105187, Russian Federation ${ }^{4}$ Russian customs Academy, Komsomolsky Av, 4, Lyubertsy, Moscow region, 140015, Russian Federation

Received: 22/12/2020

Accepted: 30/08/2020

Published: 20/09/2020

\begin{abstract}
One of the most promising areas for the development of the domestic economy is the agricultural sector which is characterized by a high level of volatility due to a wide range of business risks including weather and seasonal changes. There are significant economic imbalances despite the active processes of automation of the agricultural sector as well as the desire of farmers to reduce the cost of production while simultaneously improving its quality. And it's largely due to imperfect approaches to price formation. One of these problematic areas is the sphere of cargo transportation of agricultural products. Now the usual ways of supporting entrepreneurs in the form of preferential loans, special tax regimes, and aid grants are no longer fully able to create optimal conditions for agricultural producers. The reason of this is the complex, multi-faceted nature of production and financial and economic relations in the agricultural sector. Above-listed tools are able to harmonize the sphere of agriculture as an economic system, however, a number of issues require the development of effective organizational and economic measures in a rather tight range. So, it is advisable to review the pricing conditions for cargo transportation of agricultural products taking into account both the weather conditions and the factor of seasonality. The authors give reasons for the need to introduce a flexible approach to the application of trade surcharges (tariff schedule) in this area. The rationale for the feasibility of correcting prices for carriers' services taking into account these factors is presented since the proposed measures reduce the surface damage of agricultural products during transportation. It leads to a longer period of sell-by-date and, that is why, obtaining additional income which more than compensates of the transportation costs increasing.
\end{abstract}

Keywords: Agriculture; Competitive environment; Condition of the road surface; General transportation problem; Price formation Tariff regulation; Weather condition

\section{Introduction}

In conditions of economic instability one of the priorities is to minimize costs while ensuring a higher level of quality in comparison with competitors. Any price increasing in this case should imply a sufficiently strong justification since the final consumer may be reoriented to lower-quality but cheaper products. At the same time several types of risks need to attract additional funding as a way to overcome them. Exchange relations participants strive to maintain an acceptable price level in the market with a known range of cost fluctuations. However, if we turn to the field of cargo transportation of agricultural products it becomes obvious that the level of risks for the carrier of cargo will differ significantly in different seasons and weather conditions. But these aspects are not always objectively reflected in the price of its services. As a result of these risks the condition of cargo delivered in different seasons and weather conditions may also differ significantly. Lost production risk has a negative impact on the financial condition of persons engaged in its processing, wholesale and retail trade. As a result it is influenced on the final price of the product paid by the consumer. In this regard we consider it necessary and possible to address the mechanism of tariff regulation. In practice there are a significant number of varieties of methods for setting tariffs (1), that could be allocated into two groups: a) methods of regulation on the base of the economically sound outlays and $b$ ) incentive regulation.

The first group consists of:

- Cost-plus regulation;

- Revenue requirement method;

- Rate-of-return regulation;

- Revenue assets base (RAB)

The second group consists of:

- Performance-based regulation (PBR);

- Yardstick regulation (YR);

- Cap regulation $(\mathrm{CR})$

In our opinion the problems of crop seasonality and weather conditions are the most complex since it is not always possible to take into account the degree of their influence when developing measures for the development of agriculture, for example, when designing special tax regimes and target programs. Thus, the most rational approach is to apply a more advanced system of tariff regulation for the transport of agricultural products.

Corresponding author: Arkadii Anatol'evich Simdiankin, Russian state university of physical education, sport, youth and tourism (SCOLIPE), Sireneviy boulevard 4, Moscow, 105122, Russian Federation. E-mail: prodanova-00@mail.ru. 


\section{Literature review}

It is established that among the weaknesses of modern Russian agriculture the most significant are transport costs as well as a high level of dependence on seasonality and weather conditions (2). In addition, the situation is complicated by the problems related to improving taxation of the agricultural sector $(3,4)$. As mentioned earlier the existing methods of supporting agriculture such as taxification and aid grant are mostly aimed at harmonizing the entire sphere of economic relations (5-8). When setting tariffs for cargo transportation it should be guided not by principles of general application but by the specifics of management at the level of a specific territory with specific climatic conditions as well as the specific condition of the road surface in each season and so on. In this regard there is an objective need to consider the relevant problems in the format of transport problems when the successful solution can determine the optimal level of the tariff taking into account the influence of environmental factors (912). Thus, the main task is: a higher economic effect is determined by an increase in the volume of products without "signs of damage" with an increasing level of tariff for transportation of agricultural products (in conditions of increasing risk due to weather and seasonal factors). This condition implies both a longer sale period and a minimum percentage of waste product (the presence of rot, loss of marketable style). It is worth noting that mathematical modeling methods are of priority in order to establish the optimal tariff value (13). Today the transport planning is closely related to the economy since it takes into account a wide range of factors that are different in nature: the level of constant and direct expenses, the profit margin, the negative impact on the environment and so on. Even when investigating a single factor in the optimization of the transport model we should take into account a significant number of nuances: fuel consumption, route length, grade in favor and much more. Subsequently, the accumulated estimates are included in the target function to further calculation of the impact of individual variables (14). We can come to the following conclusion: modern transport problems take into account the degree of influence of a wide range of external and internal factors but the issues of economic justification of the impact of seasonality and weather conditions on the system of agricultural cargo transportation - from the perspective of price formation - do not always remain sufficiently developed (15-17). The allocation of cargo transportation of agricultural products to a separate problem area is due to the fact that the processes in the studied area are influenced by a significant number of additional external factors including the seasonality of the crop and weather conditions. These nuances should be taken into account in the "pricing process" since they directly affect the features of vehicle operation, on the one hand, and the level of damage to the cargo, on the other hand. In other words, the economic interests of producers, transport companies and ultimate customers (wholesale and retail trade) directly depend on the pricing models used in the system of agricultural cargo transportation.

The elimination of imbalances in the development of the agricultural sector is a problem that deserves special attention especially in the light of the conditions of global economic instability. Historical experience of the development of economic relations clearly demonstrates that in the conditions of crisis and financial market volatility the real sector of the economy acquires the role of a stabilizing factor while ensuring employment and infrastructure development. Since agriculture is the most important part of the real sector, on the one hand, and tariff regulation is a factor of increasing economic security $(18,19)$, on the other hand, it is worth considering the specifics of applying alternative approaches to the justification and calculation of tariffs in this area. In particular, the tariff regulation is a very effective tool for economic impact and it's able to harmonize the system of financial and economic relations in a specific set range - not only the high influence of the regional factor is taken into account $(20,21)$ but also the specifics of a definite branch of the economy. Let's turn to the historical aspect of the range of issues under consideration. At the beginning of this millennium issues of customs and tariff regulation of agriculture were considered in a separate order in the context of Russia's accession to the WTO (22). Later Frolova and Boyko and then the emphasis was placed on the need to implement measures of state support for agriculture that fit into the laws and requirements of the WTO since the agricultural sector has become positioned as a sphere for creating investment projects in the context of international cooperation (23). At this moment it seems appropriate to approach this issue in a completely different way, namely, to develop effective approaches to pricing in the format of a tariff system. And these very tariffs provide a faster final economic effect when there is the introduction of a progressive scale of trade allowances for the services of carriers (depending on external environmental conditions) (24-29). At the same time the final consumer is insured against fluctuations in prices since the trade premium for seasonality and weather conditions (it's charged by the cargo carrier) is compensated by a larger amount of goods delivered to the wholesale and retail trade with higher quality (30-36). Thus, without taking into account the local characteristics of a particular territorial unit it is impossible to completely realize full potential of the domestic agricultural sector. In our opinion an effective way is to introduce improved methods of tariff regulation at the regional and local levels.

\section{Basic part}

It is known that a mathematical model describing the cargo transportation from several suppliers to several consumers is described as follows:

$$
\left\{\begin{array}{c}
\mathrm{C}=\sum_{i=1}^{n} \sum_{j=1}^{m} x_{i j} c_{i j} \rightarrow \min \\
\forall x_{i j} \geq 0, \\
\forall c_{i j} \geq 0,
\end{array}\right.
$$

where $c_{i j}$ is tariff, $x_{i j}$ is cargo transported on the route with the tariff $c_{i j}$. This model describes the general conditions of transportation at known tariffs, the demand for a homogeneous cargo from consumers and the ability to meet this demand from suppliers. A one-time tariff for cargo transportation from point "A" to point "B" does not allow taking into account the preservation of cargo during transportation - especially for damage-sensitive cargo in particular fruit and vegetable products. At the same time the ratio of the "quality" of the cargo at the initial points and final destinations is also not taken into account. In real conditions the preservation ability of agricultural cargo is significantly affected by fluctuations in the vehicle body due to bad weather conditions (for example, swaying of the body by flow of wind) or unsatisfactory condition of the road surface. 

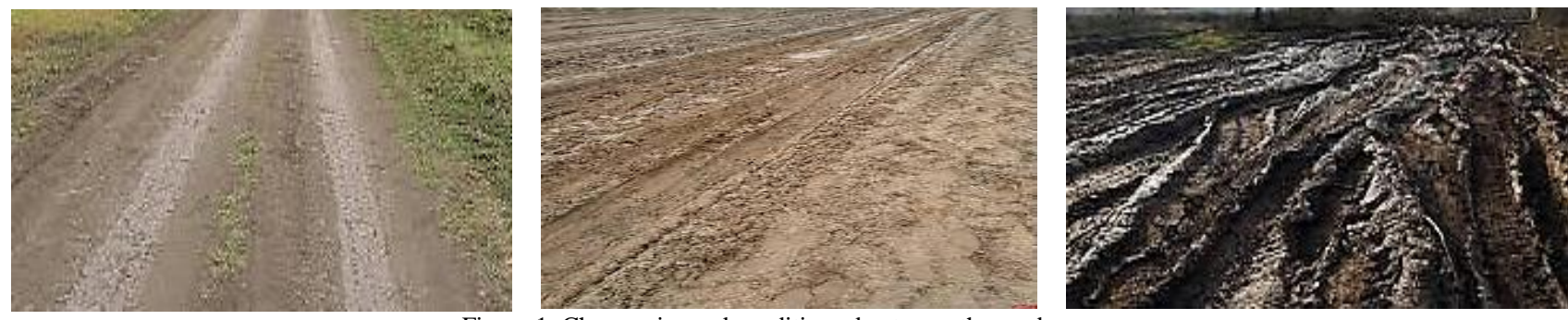

Figure 1: Changes in road conditions due to weather and season

At the same time, weather conditions can also significantly affect to the condition of the road surface if we are talking, for example, about natural roads (Fig. 1). The authors propose to take into account the impact of weather and road conditions on cargo transportation by cutting off (if possible) routes that are actually or potentially affected by them. To change or completely "cut off" routes it is proposed to use an increased tariff bringing it to a prohibitive one in cases such as the use of natural roads in heavy rain or snowfall, strong winds on open part of road, spring flooding etc. Then, taking into account the weather and road conditions formula (1) will look like this:

$$
\left\{\begin{array}{c}
\mathrm{C}=\sum_{i=1}^{n} \sum_{j=1}^{m} x_{i j}\left(c_{i j}+\max \left(c_{i j}^{r} ; c_{i j}^{w}\right)\right) \rightarrow \min , \\
\forall x_{i j} \geq 0, \\
\forall c_{i j} \geq 0, \\
0-\text { for highway, } \\
c_{i j}^{r}=\left\{\begin{array}{c}
\text { for another types of the road, } \\
>0-\text { for }
\end{array}\right. \\
c_{i j}^{w}=\left\{\begin{array}{c}
0-\text { for dry windless weather in summer }, \\
>0-\text { for other weather conditions and seasons, }
\end{array}\right.
\end{array}\right.
$$

where $c_{i j}^{r}$ is correctional tariff for road surface and its condition; $c_{i j}^{w}$ is correctional tariff for weather conditions. The modified general transportation problem table with (2) will look as shown in Table 1. Total tariffs may be determined by summation or multiplication of the "weight coefficients" to the basic tariffs. Three types of the so-called transfer function can be used to estimate the weight coefficients (Fig. 2). The linear function (Fig. 2, a) allows to increase the weight coefficient when conditions change but it cannot take into account quick and pronounced changes such as weather conditions when we need to prohibit movement along a certain route. A linear tariff increase for this rout may not lead to forming a "prohibitive" tariff but only equalize it or slightly exceed the tariff for the existing alternative route. The sigmoidal function (Fig.2, b) has the property of amplifying weak signals better than strong ones as well as preventing saturation from strong signals coming simultaneously with weak ones that allows to "customize" the tariffs more precisely. The threshold function (Fig. 2, c) when approaching unfavorable weather conditions (heavy rain, wind, snow etc.) or seasons (spring in most regions of the Russian Federation is characterized by flooding conditions and autumn - morning and evening frosts) will allow to "cut off" the possibility of transporting cargo on certain routes by setting a prohibitive tariff $c_{i j}^{w}$ equal to, for example, infinity. The weighing coefficient can be selected in various ways - one of which, perhaps, most accurately describes the condition of the road surface that affects the transport of cargo-acceleration (Table 2). In this case both linear and sigmoidal functions can be used to describe the tariff $c_{i j}^{r}$.

Table 1: Example of filling in a general transportation problem table with correctional tariffs that describe weather and road conditions

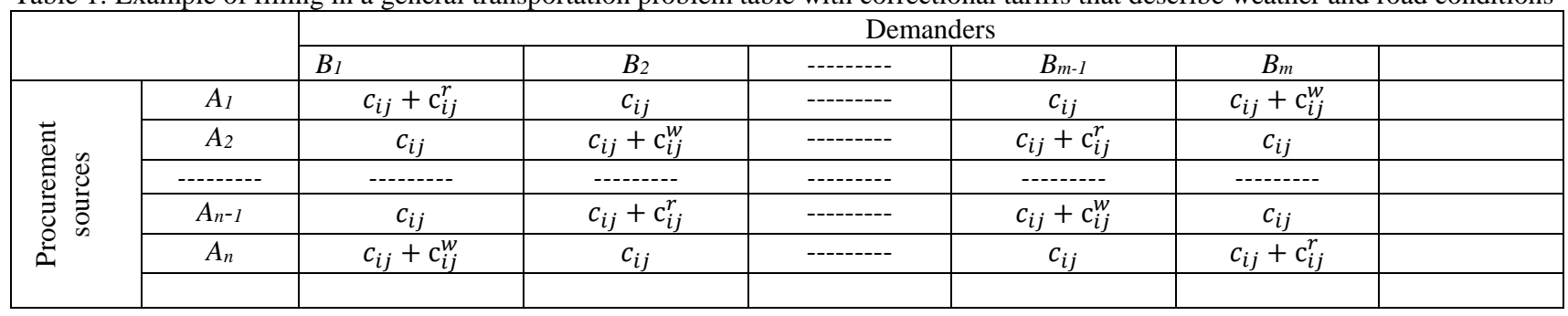

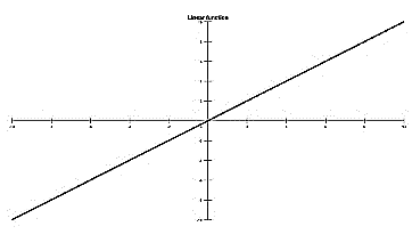

$\mathrm{a}$

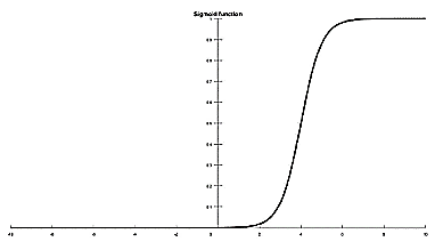

b

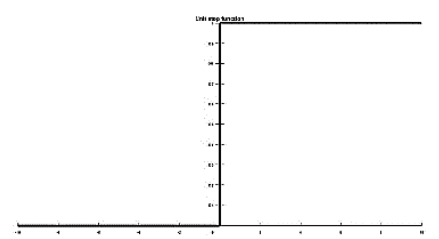

Figure 2: Transfer functions 
Table 2: Coefficients determining the permissible amplitude of vehicle vibrations

\begin{tabular}{|l|l|l|}
\hline \multirow{2}{*}{ Crop } & \multicolumn{2}{|l|}{ Empirical coefficients } \\
\cline { 2 - 3 } & $\mathrm{H}, \mathrm{m} / \mathrm{s}^{2}$ & $\mathrm{P}, \mathrm{m} / \mathrm{s}$ \\
\hline Apples & $0,3 \ldots 1,42$ & $5,03 \ldots 5,22$ \\
Red tomato & $2,83 \ldots 4,3$ & $5,46 \ldots 5,70$ \\
Green tomato & $4,24 \ldots 7,0$ & $5,70 \ldots 6,16$ \\
Field-fresh potatoes & $5,62 \ldots 7,0$ & $5,93 \ldots 6,16$ \\
Melons and pumpkins & $5,62 \ldots 8,38$ & $5,93 \ldots 6,38$ \\
Plums & $5,62 \ldots 11,14$ & $5,93 \ldots 6,83$ \\
Cucumbers & $8,38 \ldots 11,14$ & $6,38 \ldots 6,83$ \\
\hline
\end{tabular}

Here is an example of calculating the total cost of cargo transportation using MS Excel taking into account the change in the tariff for a certain rout of cargo transportation due to deterioration weather. Choose real routes on the map of the Ryazan region of the Russian Federation - apple gardens in the Vishnevka village of Oktyabrsky district of the Ryazan region - to simulate transportation. These closes $1,2,3$ are apple gardens, $4-\mathrm{a}$ food store, 5 - a warehouse, $6-$ a mini-factory for processing fresh apples into juice. Let's define potential transportation routes from all closes to the store, warehouse, and mini-factory. We neglect the transportation of apples within closes 1-3 and take into account only the routes from their nearest border to the destination - a store, warehouse, mini-factory. Then the routes will look like this (Fig. 3). Figure 4 clearly shows that routes 1-5, 1-6, 2-5 (completely on natural roads besides rout 1-6 - crosses a ravine) depend significantly on weather conditions and the season; routes 1-4, 2-4, 3-6 (part of the route passes on natural roads) partially depend on these conditions; other routes do not depend on the above conditions since they pass on asphalt roads. We will exclude from consideration the condition of asphalt surface on these road sections due to the short length of the route besides assuming that the speed of the vehicle is low. Consequently, for routes 1$5,1-6,2-5$ - increasing weight coefficients can be introduced up to prohibitive (sigmoidal function) and for 1-4, 2-4, 3-6 linearly increasing the tariff weight coefficients.

The initial weight coefficients can be obtained both on the basis of evaluation of statistics of damage and safety of the products transported on these routes in different weather conditions and on the basis of assessment of, for example, acceleration during the transportation process directly. Then these data can be used for plot of nomograms connecting the tariff change and the state of the road surface and vehicle speed on it. Let's draw up a general transportation problem table and set tariffs (in rubles per ton of cargo) for dry and windless summer weather taking into account the length of the route and the geographical features of the area. Let's randomly assign apple stocks on garden 1-3 in tons and set the demand for products store, warehouse and mini-factory for the production of apple juice also in tons (Table 3). The solution for this table in MS Excel has the following form (Fig. 4, a). Let's change the tariffs due to changes in weather conditions when it is either dangerous to move along routes $1-5,1-6,2-5$ or fluctuations in the vehicle body increase significantly because of the deterioration of the road surface that can cause the increasing the fruit surface damage. This is especially true for route 1-6 which passes through a ravine - in bad weather it can become a "trap" for the vehicle. Let's use a prohibitive tariff for this route equating it to the sum of all the routes' tariffs as well as use double tariff for routes 1-5 and 2-5 (Fig. 4, b). It is clearly visible that route 1-6 is excluded from the schedule of transportation of products but the cost of transportation increases. In these circumstances the manager (owner) should decide to solve this dilemma - either accept the risks of saving the route if the conditions change or flexibly change the route understanding that this will ultimately save the equipment, products and, possibly, the life of the driver of the vehicle. It should also be noted that for a mini-factory the damaged products are not so "critical" if they are immediately sent for processing. However, the repair costs of vehicle components can significantly exceed the difference between the cost of transportation in warm and dry summer weather and spring mud.

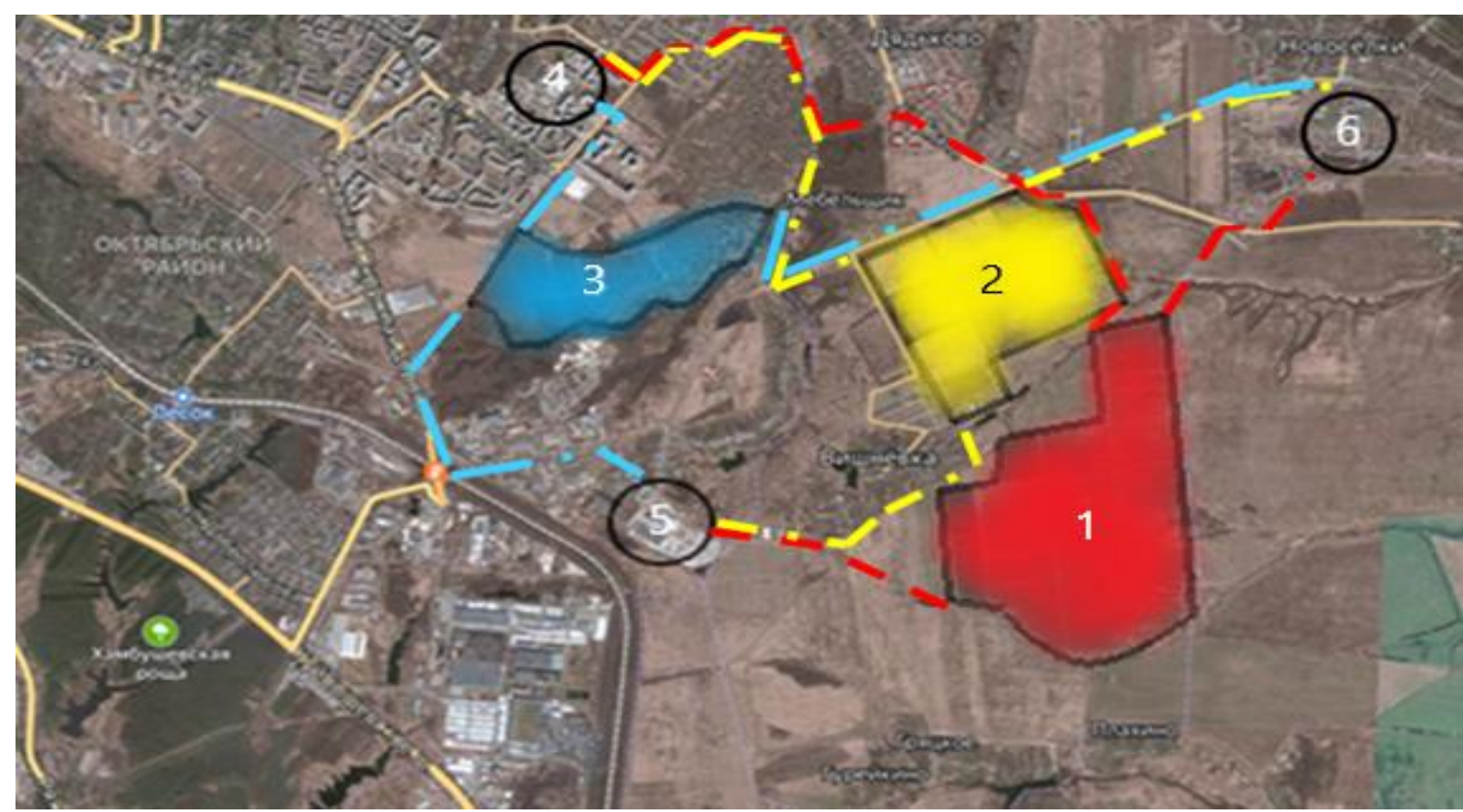

Figure 3: Routes from apple gardens 1-3 to store 4, warehouse 5 and mini-factory 6: routes 1-4, 1-5, 1-6 are highlighted in red; routes 2-4, 2-5, 2-6 are highlighted in yellow; routes 3-4, 3-5, 3-6 are highlighted in blue 
Table 3: General transportation problem table for dry and windless summer weather

\begin{tabular}{|c|c|c|c|c|c|}
\hline & \multicolumn{4}{|c|}{ Demanders } \\
\hline & & $B_{1}$ (Shop 4) & $B_{2}($ Warehouse 5$)$ & $B_{3}($ Mini-factory 6$)$ & Stocking \\
\hline \multirow{4}{*}{ 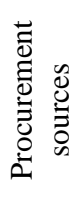 } & $A_{1}($ Garden 1) & 6 & 3 & 4 & 40 \\
\hline & $A_{2}($ Garden 2) & 5 & 3 & 1 & 30 \\
\hline & $A_{3}$ (Garden 3) & 1 & 2 & 3 & 20 \\
\hline & Wants & 15 & 40 & 35 & 90 \\
\hline
\end{tabular}

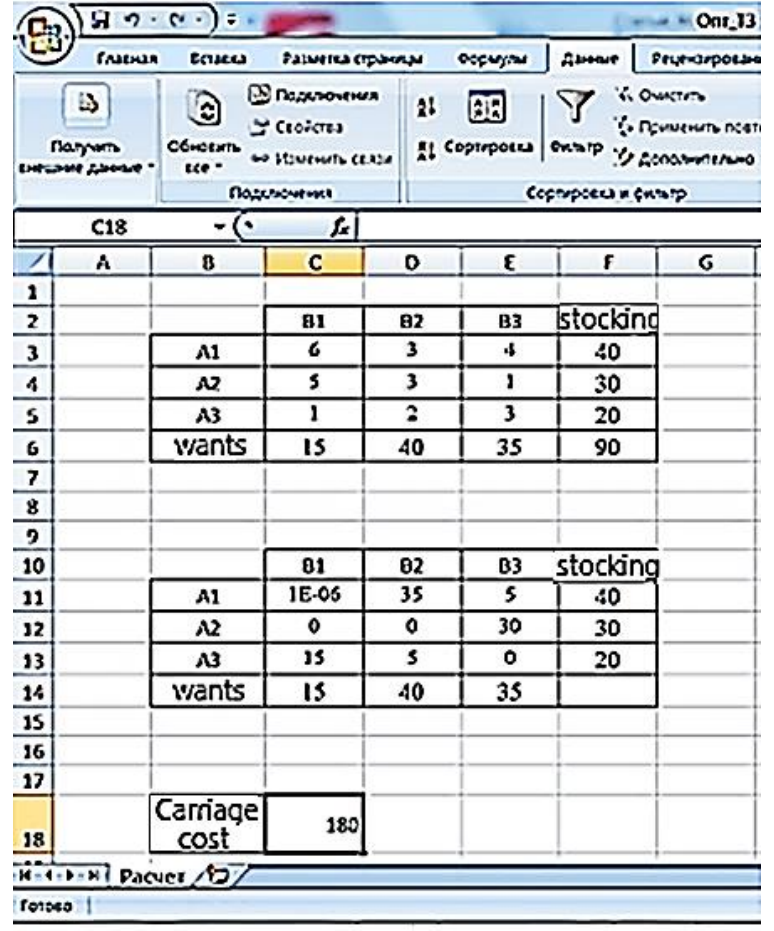

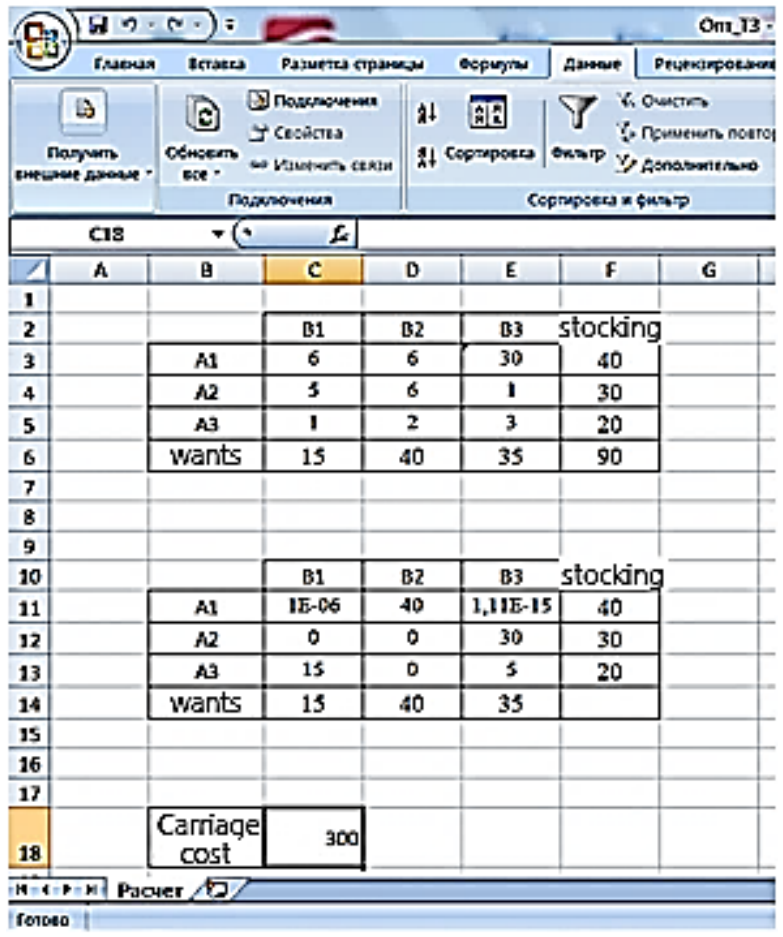

Figure 4: Solution of transportation problem table with with the original tariffs (a) and increased tariffs due to weather conditions (b)

\section{Conclusions}

The proposed method of accounting for natural-climatic and road conditions in tariffs will allow us to clarify them by introducing weight coefficients that change tariffs up to prohibitive ones according to the linear, threshold or sigmoidal function. Although the total cost of transportation under the proposed approach will increase relative to the original optimized solution but this increase will be offset by a reduction in the cost of repairing vehicles. In addition, reducing the fruits surface damage will allow to sell them for a longer period of time which will also increase the overall profit.

\section{Ethical issue}

Authors are aware of, and comply with, best practice in publication ethics specifically with regard to authorship (avoidance of guest authorship), dual submission, manipulation of figures, competing interests and compliance with policies on research ethics. Authors adhere to publication requirements that submitted work is original and has not been published elsewhere in any language.

\section{Competing interests}

The authors declare that there is no conflict of interest that would prejudice the impartiality of this scientific work.

\section{Authors' contribution}

All authors of this study have a complete contribution for data collection, data analyses and manuscript writing.

\section{References}

1. Pronina NN. Comparative characteristics of cost-based methods for setting energy tariffs. Bulletin of the Samara State Technical University. Series: Economic Sciences. 2014;1(11):102-106.

2. Kirillova OV. Priority directions of ensuring food security in Russia taking into account the analysis of the strengths and weaknesses of the country's economy. Bulletin of Kazan State Agricultural University. 2019;2(53):150-153.

3. Pinskaya MR. Tax policy in the field of regulation of the agricultural sector of the economy in the conditions of Russia's membership in the EEU. Izvestiya TSHA. 2017;4:99-113.

4. Masood O, Tvaronavičienė M, Javaria K. Impact of oil prices on stock return: evidence from G7 countries. https://doi.org/10.9770/ird.2019.1.2(4)

5. Aleksandrovich LV, Pavlovna KP, Kimovich TI, Sergeevich TD Development of smart well units for multilayer reservoirs operated with the system of simultaneous-separate exploitation. Journal of Applied Engineering Science. 2018;16(4):561-4. doi:10.5937/jaes16-17676

6. Chen T, Babanin A, Al-Qāsim MA, Chapron B, Chen J, Md SH Prototype of web-based daily work report management system using smart pens. Journal of Applied Engineering Science. 2019;17(3):280-3.

7. Akhmetshin EM, Dzhavatov DK, Sverdlikova EA, Sokolov MS, Avdeeva OA, Yavkin GP. The influence of innovation on social 
and economic development of the Russian regions. European Research Studies. 2018;21:767-76.

8. Bondarenko A, Islamov S, Mardashov D. Features of oil well killing in abnormal carbonate reservoirs operating conditions. InEngineering and Mining Geophysics 2019 15th Conference and Exhibition 2019 Apr 16 (Vol. 2019, No. 1, pp. 1-5). European Association of Geoscientists \& Engineers.

9. Dunets AN, Vakhrushev IB, Sukhova MG, Sokolov MS, Utkina KM, Shichiyakh RA. Selection of strategic priorities for sustainable development of tourism in a mountain region: concentration of tourist infrastructure or nature-oriented tourism. Entrepreneurship and Sustainability Issues. 2019;7(2):1217-29. https://doi.org/10.9770/jesi.2019.7.2(29)

10. Filatova I, Shabalov M, Nikolaichuk L. Regulation methods in natural monopoly markets case of russian gas network companies. International Journal of Engineering Research and Technology. 2019;12(5):624-30.

11. Poltarykhin A, Dibrova Z, Kovaleva I, Vasyutkina L, Potekhina E, Zinisha O. World experience in the application of antitrust regulation and compliance system. Entrepreneurship and Sustainability Issues. 2020;7(3):2313-2325.

12. Ivanova TS, Malarev VI, Kopteva AV, Koptev VY. Development of a power transformer residual life diagnostic system based on fuzzy logic methods. InJournal of Physics: Conference Series 2019 Nov (Vol. 1353, No. 1, p. 012099). IOP Publishing. doi:10.1088/1742-6596/1353/1/012099

13. Tawfik C, Limbourg S. Bilevel optimization in the context of intermodal pricing: state of art. Transportation Research Procedia. 2015 Jan 1;10:634-43.

14. Serrano-Hernández A, Álvarez P, Lerga I, Reyes-Rubiano L, Faulin J. Pricing and internalizing noise externalities in road freight transportation. Transportation Research Procedia. 2017 Jan 1;27:325-32.

15. Ivanova V, Poltarykhin A, Szromnik A, Anichkina O. Economic policy for country's digitalization: A case study. Entrepreneurship and sustainability issues. 2019;7(1):649-61. http://doi:10.9770/jesi.2019.7.1(46)

16. Jafarpour H, Moghadasi J, Khormali A, Petrakov DG, Ashena R. Increasing the stimulation efficiency of heterogeneous carbonate reservoirs by developing a multi-bached acid system. Journal of Petroleum Science and Engineering. 2019 Jan 1;172:50-9. doi:10.1016/j.petrol.2018.09.034

17. Movchan IB, Yakovleva AA. Refined assessment of seismic microzonation with a priori data optimisation. Записки Горного института. 2019;236. doi:10.31897/PMI.2019.2.133

18. Maximov YuA. The main directions of improving customs and tariff regulation as a factor of ensuring economic security. Journal of legal and economic research. 2009;1:97-100.

19. Aleksandrova TN, Nikolaeva NV, Potemkin VA. Beneficiation of carbonaceous rocks: New methods and materials. InInnovation-Based Development of the Mineral Resources Sector: Challenges and Prospects-11th Conference of the Russian-German Raw Materials 2018 Oct 11 (pp. 391-398).

20. Galushko DV. Some aspects of tariff regulation in the regions of the Russian Federation. Bulletin of the Bryansk State University. 2014;3:30-35.

21. Podoprigora DG, Korobov GY, Bondarenko AV. Acid stimulation technology for wells drilled the low-permeable hightemperature terrigenous reservoirs with high carbonate content. International Journal of Civil Engineering and Technology. 2019;10(1):2680-96.

22. Petkova AR, Maksutov IR. Customs and tariff regulation of agriculture in the light of Russia's accession to the WTO. In the collection: Models of indicative planning of socio-economic development of rural territories materials of the international scientific and practical conference. 2006:218-220.

23. Frolova NS, Boyko TS. Agriculture in the conditions of Russia's participation in the WTO: status, problems, prospects. Problems of modern economy. 2015;4(56):312-315.
24. Kuzhaeva, A., Dzhevaga, N., \& Berlinskii, I. Modernization of catalyst systems for the processes of hydrocarbon conversion to synthesis gas. ARPN Journal of Engineering and Applied Sciences, 2019, 14(20), pp. 3535-3543

25. Kuzmin, P. A., Bukharina, I. L., \& Kuzmina, A. M. The reaction of woody plants to growing conditions in the man-made environment. International Journal of Civil Engineering and Technology, 2018, 9(11), 878-887.

26. Zhadovskiy, I.T., Berlinskiy, I.V., Vasiliev, V.V., Stogov, A.V. Influence of the content of caluminate on their physicochemical properties. Journal of Physics: Conference Series, 2019, 1384(1),012072

27. Zaripova, R. S., Ahmetova, M. H., \& Kuzmin, P. A. Ecological and biological features of quickbeam (sorbus aucuparia L.) in the context of an urbanized environment. Journal of Advanced Research in Dynamical and Control Systems, 11(5 Special Issue), 2019, 1731-1734.

28. Kuznetsov, V. S., Suprun, I. K., \& Petrov, D. S. Assessment and reduction of drilling waste impact on the environment components. Neftyanoe Khozyaystvo - Oil Industry, 2017, (1), 94-95.

29. Bukharina, I. L., Zhuravleva, A. N., Dvoeglazova, A. A., Kamasheva, A. A., Muhametnagimovna, S. A., \& Kuzmin, P. A. Physiological and biochemical characteristic features of smallleaved lime(tilia cordata mill.) in urban environment. Advances in Environmental Biology, 2014, 8(13), 79-83.

30. Petrov, D., \& Movchan, I. Comprehensive evaluation of anthropogenic load on environment components under conditions of ferroalloys manufacture. Ecology, Environment and Conservation, 2017, 23(1), 539-543.

31. Puryaev, A., \& Puryaev, A. Evaluating the Effectiveness of Projects of Global and National Economic Significance Level. In Smart Innovation, Systems and Technologies (Vol. 172, pp. 317 331). 2020, Springer, Singapore. https://doi.org/10.1007/978981-15-2244-4_29

32. Nureeva, G. I., Mingazova, L. I., Ibrayeva, A. T., \& Faridovna, K. G. Literary drawing room: Children's poetry translated by $r$. minnullin. Journal of Sociology and Social Anthropology, 2019, 10(4), 186-191. doi:10.31901/24566764.2019/10.04.310

33. Kuznetsov, V. S., \& Suprun, I. K. The assessment of alumina production waste impact on natural water. Journal of Ecological Engineering, $\quad 2018, \quad 19(2), \quad$ 154-158. doi:10.12911/22998993/82267

34. Prischepa, O. M., Nefedov, Y. V., \& Kochneva, O. E. Raw material base of hard-to-extract oil reserves of russia. [Matériaprima base de reservas de óleo de difícil extração da Rússia] Periodico Tche Quimica, 2020, 17(34), 915-924.

35. Movchan, I. B., \& Yakovleva, A. A. Wave analogies for generalized description of geodynamic zones. International Journal of Innovative Technology and Exploring Engineering, 2019, 8(6), 863-868.

36. Rahman, P. A., \& Novikova Freyre Shavier, G. D. Reliability model of disk arrays RAID-5 with data striping. IOP Conference Series: Materials Science and Engineering, 2018,. 327(2). https://doi.org/10.1088/1757-899X/327/2/022087 